\title{
The association between coffee consumption and periodontitis: a cross-sectional study of a northern German population
}

\author{
Julia Struppek $k^{1,2} \cdot$ Carolin Walther $^{1,2}\left(\right.$ Kübra Bunte $^{2} \cdot$ Birgit-Christiane Zyriax $^{3} \cdot$ Jan-Per Wenzel ${ }^{4}$. \\ Juliana Senftinger ${ }^{4}$ Julius Nikorowitsch ${ }^{4}$. Guido Heydecke ${ }^{1}$ - Udo Seedorf ${ }^{1,2} \cdot$ Thomas Beikler $^{2} \cdot$ Katrin Borof $^{1,2,5}$. \\ Carola Mayer ${ }^{6} \cdot$ Ghazal Aarabi $^{1,2}$
}

Received: 2 August 2021 / Accepted: 24 September 2021 / Published online: 7 October 2021

(c) The Author(s) 2021

\begin{abstract}
Background Positive and negative influences on oral health are attributed to coffee consumption. The aim of the current study is to evaluate the association between coffee consumption and periodontitis in the general population of Hamburg. Methods A total of 6,209 participants from the Hamburg City Health Study were included in this cross-sectional study. Information on coffee consumption was collected using a food frequency questionnaire. Periodontal examination included assessment of dental care ability via Plaque Index, measurement of pocket depth, gingival recession, and bleeding on probing. Classification was based on the criteria of Eke and Page. Ordinal logistic regression models were performed unadjusted and adjusted for confounding variables.

Results Periodontal cohort consists of 6,209 participants, presenting either none/mild ( $n=1,453,39.6 \%$ men, $2.4 \%$ strong coffee drinkers), moderate ( $n=3,580,49.3 \%$ men, $3.3 \%$ strong coffee drinkers), or severe $(n=1,176,60.9 \%$ men, $5.0 \%$ strong coffee drinkers) periodontitis. There was a significant association between strong coffee consumption ( $\geq 7$ or more cups/day) and periodontitis (OR: 1.51; CI: 1.07, 2.12; $p>0.001$ ), compared with low coffee consumption. Conversely, moderate coffee consumption was not associated with periodontitis, compared with low coffee consumption.

Conclusion and clinical relevance.

In this cross-sectional study of a northern German population, strong coffee consumption was significantly associated with periodontitis. Influence of changes in coffee consumption on periodontal disease etiology/progression should be investigated in future prospective study designs, in order to identify strong coffee consumption as a potential risk factor of periodontitis.
\end{abstract}

Keywords Coffee · Periodontitis · Oral health · Gingival recession · Gingival pocket · Cross-sectional studies · Confounding factors $\cdot$ Epidemiologic

Julia Struppek and Carolin Walther are co-first author.

Carolin Walther

c.walther@uke.de

1 Department of Prosthetic Dentistry, Center for Dental and Oral Medicine, University Medical Center HamburgEppendorf, Hamburg, Germany

2 Department of Periodontics, Preventive and Restorative Dentistry, University Medical Centre Hamburg-Eppendorf, 20246 Hamburg, Germany

3 Midwifery Science - Health Service Research and Prevention, Institute for Health Services Research in Dermatology and Nursing (IVDP), University Medical Center Hamburg-Eppendorf (UKE), Hamburg, Germany

4 Department of General and Interventional Cardiology, University Heart and Vascular Center, Hamburg, Germany

5 Epidemiological Study Center, University Medical Center Hamburg-Eppendorf, Hamburg, Germany

6 Department of Neurology, University Medical Center Hamburg-Eppendorf, Hamburg, Germany 


\section{Introduction}

Oral diseases affect approximately half of the global population, with severe periodontitis being one of the most prevalent non-communicable diseases [1-3]. Periodontitis is a chronic inflammatory disease of the tooth supporting tissues, characterized by deep periodontal pockets, bleeding gingiva, and alveolar bone loss. Dysbiosis of the oral microbiome [4] is suggested to induce a disproportionate host inflammatory and immune reaction (e.g., interleukin-6, tumor necrosis factor alpha, C-reactive protein [5, $6]$ ), resulting in periodontal damage in susceptible individuals. Additionally, genetic predisposition [7], epigenetics [8], lifestyle [9, 10], nutrition [11, 12], and presence of chronic inflammation [13] are independent risk factors for disease progression. Coffee is one of the most consumed beverages worldwide [14]. A total of $395 \mathrm{~mL} /$ day $(\sim 2$ cups per day) of coffee are consumed in Germany [15]. Although coffee consumption is so common, the literature is still reporting both protective [16] and destructive [17] mechanisms to preserve/degrade periodontal tissue. Caffeine has antioxidant and anti-inflammatory effects by reducing reactive oxygen species and serum pro-inflammatory cytokines, respectively [16]. Chlorogenic acid from coffee demonstrated a direct inhibitory effect on Porphyromonas gingivalis, a major pathogen key-player of periodontitis [16] and can indirectly affect the bioavailability of other nutrients and thereby modulate periodontal disease prevalence [18]. A few studies suggest an association between coffee intake and periodontitis [19-23]. The US Department of Veterans Affairs Dental Study included 1,231 participants and reported no harmful but rather a beneficial effect of coffee on periodontal health [22]. A Korean population-based study reported higher tooth loss in participants with daily coffee intake, compared with those only drinking coffee less than once a month [19].

Therefore, the aim of the current study is to evaluate the potential association between coffee consumption and periodontitis using state-of-the-art, comprehensive phenotyping derived from the Hamburg City Health Study (HCHS).

\section{Material and methods}

\section{Study participants and design}

The Hamburg City Health Study (HCHS) is an ongoing prospective, population-based cohort study at the University Medical Center Hamburg-Eppendorf which commenced 2016 with the receipt of the ethical approval
(PV5131). The study has been registered at ClinicalTrials. gov (NCT039934957). HCHS aims to investigate several important risk and prognostic factors in major chronic diseases [24]. The HCHS is in accordance with the current revision of the Declaration of Helsinki [25], the ethical principles described by Good Clinical Practice (GCP) and by Good Epidemiological Practice (GEP). Participants between 45 and 74 years of age from the general population of Hamburg were recruited. Written informed consent was obtained from all participants. Inclusion criteria included a completed periodontal examination and documentation on coffee consumption data. Exclusion criteria included individuals requiring endocarditis prophylaxis.

\section{Determination of coffee consumption parameters}

Coffee consumption was assessed using a previously validated food frequency questionnaire (FFQ) [26] that included cups of coffee consumed per day for the last 12 months, type of coffee (caffeinated or decaffeinated), and additives (no additives, sweetener, milk, evaporated milk, sugar, or honey). Multiple answers were possible for type of coffee and additives. Frequency of coffee consumption was classified as low (0-2 cups/day), moderate (3-6 cups/day), and strong ( $\geq 7$ or more cups/day).

\section{Determination of periodontal parameters}

Oral and periodontal examination was carried out by trained and calibrated study nurses. The decayed, missing, and filled teeth (DMFT) index was recorded and periodontal examination was carried out with a PCP-12 probe except for third molars. Probing depths (PD) and gingival recessions (GR) were recorded in 6 sites (mesio-oral, oral, distooral, mesio-buccal, buccal, disto-buccal) for each tooth in millimeters. Clinical attachment loss (CAL) was calculated $(\mathrm{CAL}=\mathrm{PD}+\mathrm{GR})$. Bleeding on probing $(\mathrm{BOP})$ and Plaque Index (PI) was recorded accordingly [27]. The diagnosis and the severity of periodontitis (none/mild, moderate and severe) was classified according to the criteria of Eke and Page [28]:

\section{Additional variables}

The additional variables, such age, sex, education (based on international standard classification of education [29]), and smoking (non-smoker, former smoker [quit smoking at least 6 month ago], current smoker), were assessed via self-reported questionnaire. In the study center, the following variables were measured: body mass index (BMI in $\mathrm{kg}$ / $\mathrm{m}^{2}$ ), diabetes mellitus (taking medication of the A10 group (ATC-Code), fasting glucose $>126 \mathrm{mg} / \mathrm{dl}$, non-fasting glucose $>200 \mathrm{mg} / \mathrm{dl}$, positive self-disclosure), coronary artery 
disease (CAD was defined as suffering from one or more of the following conditions: status post myocardial infarction, percutaneous coronary intervention (PCI) or history of coronary bypass surgery), hypertension (was defined as a systolic blood pressure $\geq 140 \mathrm{mmHg}$, a diastolic blood pressure $\geq 90 \mathrm{mmHg}$, or the use of one or more of the following antihypertensive drugs: ACE inhibitors, angiotensin II receptor blockers, beta blockers, calcium channel blockers, renin inhibitors, or loop diuretics), and laboratory parameters (serum high-sensitive IL-6 and high-sensitive CRP).

\section{Statistical analyses}

Descriptive analyses were performed for all variables stratified by periodontitis severity. Continuous variables were presented as median and interquartile range [median (IQR)] and categorical variables were presented as absolute numbers and percentages $[n(\%)]$. Ordinal logistic regression models were used to test hypotheses and to determine the association between periodontitis (dependent variable) and coffee consumption (independent variable; low coffee consumption served as reference group). Models were stepwise adjusted (model 1: unadjusted; model 2: adjusted for confounders: age, sex, smoking, diabetes, and hypertension). Results of the associations are reported as odds ratios (OR) with $95 \%$ confidence intervals $(95 \% \mathrm{CI})$ and $p$-values. All statistical analyses were performed in Page R software version 4.1.0 (R Project for Statistical Computing) with $p$-values $<0.05$ interpreted as statistical significance.

\section{Results}

\section{Descriptive statistics}

Overall cohort consists of 10,000 participants with $48.9 \%$ being men with a median age of 63 years. Of the participants, $63.3 \%$ of them were low ( $0-2$ cups/day), $33.3 \%$ moderate (3-6 cups/day), and 3.5\% strong ( $\geq 7$ cups/day) coffee drinkers. Periodontal cohort consists of 6,209 participants, presenting either none/mild ( $n=1,453,39.6 \%$ men, $2.4 \%$ strong coffee drinkers), moderate ( $n=3,580,49.3 \%$ men, $3.3 \%$ strong coffee drinkers), or severe $(n=1,176,60.9 \%$ men, 5.0\% strong coffee drinkers) periodontitis. The baseline characteristics of the study participants stratified by periodontitis severity are presented in Table 1 (and categorized for coffee consumption as Table S1). Participants with severe periodontitis were more often men (60.9\%) with median age of 66 years, $4.1 \%$ exhibit a lower education, and $25.1 \%$ were currently smoking. Furthermore, $11.3 \%$ were diabetic and $72.5 \%$ suffered from hypertension. Five percent of participants with severe periodontitis drunk $\geq 7$ cups of coffee per day.

\section{Association between coffee consumption and periodontitis}

Ordinal logistic regression analyses revealed significant association between strong coffee consumption and periodontitis in the unadjusted (OR: 1.52; 95\% CI: 1.10, 2.09; $p>0.001)$ and adjusted (age, sex, smoking, diabetes, and hypertension) model (OR: 1.51; CI: $1.07,2.12 ; p>0.001$ ) in comparison with low coffee consumption (Table 2). Conversely, moderate (3-6 cups/day) coffee consumption was neither associated in the unadjusted nor in the fully adjusted model with periodontitis, compared with low coffee consumption.

\section{Discussion}

The current study included comprehensive phenotypical data from 6,209 participants with complete periodontal examination and documentation of coffee consumption in order to determine a potential association. Participants with severe periodontitis were more often men with median age of 66 years. After adjusting for potential confounders (age, sex, smoking, and diabetes mellitus), strong coffee consumption was significantly associated with periodontitis compared to participants with low coffee consumption. In contrast, moderate (3-6 cups/day) coffee consumption was not associated with periodontitis in comparison to low coffee consumption.

Few studies confirmed a negative association of coffee on oral health [19, 20, 30-32]. Longitudinal data from the Korean National Health and Nutrition Examination Survey (KNHANES) $(n=16,730)$ revealed higher consumption of coffee in men with periodontitis [20]. Highest coffee consumption ( $\geq 3$ cups/day) in the KNHANES study overlaps with moderate coffee consumption (3-6 cups/day) defined for the current study. In contrast, the current study revealed no significant association between moderate coffee consumption and periodontitis when compared to low coffee consumption. But, the small fraction of 'strong coffee consumers' ( $>7$ cups/day) were significantly associated with periodontitis. The literature describes a potential mechanism: caffeine causes harmful effects on bone metabolism by directly influencing the signaling cascade that leads to cell death of osteoblasts [33] and/or indirectly by increased excretion [34] or decreasing absorption [35] of calcium.

Varying periodontal classification protocols challenge a meaningful comparison of our results to prior studies. For example, two cross-sectional studies observed a significant association between daily coffee consumption and tooth loss [19, 32], thus reporting solely the absolute endpoint of disease manifestation. In the current study, we used the gold standard to report periodontal diseases 
Table 1 Baseline characteristics of the study population classified by the degree of periodontitis

\begin{tabular}{|c|c|c|c|c|}
\hline \multirow[t]{2}{*}{ Characteristics } & \multirow[b]{2}{*}{ Overall cohort } & \multicolumn{3}{|l|}{ Periodontitis } \\
\hline & & None/mild PA & Moderate PA & Severe PA \\
\hline Number of participants & 10,000 & 1,453 & 3,580 & 1,176 \\
\hline \multicolumn{5}{|l|}{ Median [IQR] or n (\%) } \\
\hline \multicolumn{5}{|c|}{ Socio-demographic characteristics } \\
\hline Female sex & $5,108(51.1)$ & $878(60.4)$ & $1,814(50.7)$ & $460(39.1)$ \\
\hline Age & $63[55,70]$ & $59[52,66]$ & $63[55,69]$ & $66[59,71]$ \\
\hline \multicolumn{5}{|l|}{ Education } \\
\hline Low & $313(3.4)$ & $43(3.1)$ & $151(4.4)$ & $55(5.0)$ \\
\hline Medium & $4,801(52.4)$ & $675(48.5)$ & $1,711(50.0)$ & $605(54.5)$ \\
\hline High & $4,052(44.2)$ & $675(48.5)$ & $1,559(45.6)$ & $450(40.5)$ \\
\hline \multicolumn{5}{|l|}{ Cardiovascular risk factors } \\
\hline \multicolumn{5}{|l|}{ Smoking } \\
\hline Current & $1,978(19.9)$ & $235(16.2)$ & $608(17.1)$ & $293(25.1)$ \\
\hline Former & $4,406(44.3)$ & $625(43.2)$ & $1,581(44.4)$ & $550(47.0)$ \\
\hline Never & $3,565(35.8)$ & $588(40.6)$ & $1,369(38.5)$ & $326(27.9)$ \\
\hline BMI & $26.13[23.53,29.21]$ & $25.56[23.01,28.67]$ & $26.02[23.55,29.01]$ & $26.45[24.11,29.65]$ \\
\hline Diabetes mellitus & $794(8.6)$ & $85(6.2)$ & $242(7.4)$ & $122(11.3)$ \\
\hline Coronary artery disease & $498(5.1)$ & $46(3.2)$ & $140(4.0)$ & $62(5.3)$ \\
\hline Hypertension & $6,301(66.1)$ & $768(54.8)$ & $2,266(66.3)$ & $810(72.5)$ \\
\hline \multicolumn{5}{|l|}{ Laboratory parameters } \\
\hline Hs CRP & $0.12[0.06,0.26]$ & $0.10[0.06,0.23]$ & $0.11[0.06,0.25]$ & $0.13[0.07,0.30]$ \\
\hline Hs IL6 & $1.64[1.18,2.39]$ & $1.47[1.03,2.08]$ & $1.57[1.16,2.23]$ & $1.80[1.34,2.69]$ \\
\hline \multicolumn{5}{|l|}{ Coffee parameters } \\
\hline \multicolumn{5}{|c|}{ Coffee consumption caffeinated } \\
\hline Low & $5,699(63.3)$ & $843(63.7)$ & $2,026(62.1)$ & $666(63.4)$ \\
\hline Moderate & $2,999(33.3)$ & 449 (33.9) & $1,127(34.6)$ & $331(31.5)$ \\
\hline Strong & $311(3.5)$ & $32(2.4)$ & $107(3.3)$ & $53(5.0)$ \\
\hline With milk & $5,428(63.4)$ & $843(67.4)$ & $1,973(63.6)$ & $617(61.5)$ \\
\hline With evaporated milk & $769(9.0)$ & $99(7.9)$ & $287(9.3)$ & $90(9.0)$ \\
\hline With sugar & $1,126(13.2)$ & $160(12.8)$ & $377(12.2)$ & $130(13.0)$ \\
\hline With honey & $77(0.9)$ & $10(0.8)$ & $20(0.6)$ & $11(1.1)$ \\
\hline With sweetener & $419(4.9)$ & $62(5.0)$ & $135(4.4)$ & $43(4.3)$ \\
\hline Black & $2,843(33.2)$ & $377(30.1)$ & $1,025(33.0)$ & $358(35.7)$ \\
\hline \multicolumn{5}{|c|}{ Coffee consumption decaffeinated } \\
\hline Low & $8,787(98.5)$ & $1,300(99.0)$ & $3,188(98.7)$ & $1,010(97.5)$ \\
\hline Moderate & $125(1.4)$ & $13(1.0)$ & $40(1.2)$ & $25(2.4)$ \\
\hline Strong & $13(0.1)$ & 0 & $3(0.1)$ & $1(0.1)$ \\
\hline With milk decaf & $1,231(60.4)$ & $191(63.0)$ & $454(61.6)$ & $118(53.2)$ \\
\hline With evaporated milk decaf & $158(7.7)$ & $21(6.9)$ & $59(8.0)$ & $23(10.4)$ \\
\hline With sugar decaf & $208(10.2)$ & $37(12.2)$ & $55(7.5)$ & $20(9.5)$ \\
\hline With honey decaf & $22(1.1)$ & $3(1)$ & $8(1.1)$ & $3(1.4)$ \\
\hline With sweetener decaf & $100(4.9)$ & $18(5.9)$ & $35(4.7)$ & $10(4.5)$ \\
\hline Black decaf & $658(32.3)$ & $88(29)$ & $236(32)$ & $84(37.8)$ \\
\hline \multicolumn{5}{|l|}{ Dental parameters } \\
\hline DMFT Index & $20[16,23]$ & $17[14,21]$ & $19[16,23]$ & $21[17,24.25]$ \\
\hline BOP & $7.69[1.92,20.37]$ & $2.08[0,7.14]$ & $8.33[2.17,19.23]$ & $21.05[9.26,41.67]$ \\
\hline Plaque Index & $8.7[0,29.17]$ & $0[0,10.71]$ & $8.7[0,27.78]$ & $21.74[5.77,54.76]$ \\
\hline
\end{tabular}

Abbreviations: BMI body mass index; BOP bleeding on probing; DMFT Index Decayed, Missing, Filled, Teeth Index; Hs CRP high-sensitivity C-reactive protein; Hs IL-6 high-sensitivity interleukin-6; decaf decaffeinated 
Table 2 Ordinal logistic regression models: outcome periodontitis, exposure coffee consumption (caffeinated)

\begin{tabular}{llll}
\hline Parameter & OR & 95\% CI & $p$-value \\
\hline Model 1 & & & \\
Moderate coffee consumption & 0.9538 & $0.8424,1.0799$ & 0.456 \\
Strong coffee consumption & 1.5202 & $1.1044,2.0913$ & $>0.001$ \\
Model 2 & & & \\
Moderate coffee consumption & 1.0196 & $0.8908,1.1669$ & 0.7782 \\
Strong coffee consumption & 1.5071 & $1.0692,2.1244$ & $>0.001$ \\
Age & 1.0511 & $1.0426,1.0598$ & $<0.001$ \\
Female sex & 0.6798 & $0.5986,0.7717$ & $<0.001$ \\
Current smoking & 1.8983 & $1.5798,2.2823$ & $<0.001$ \\
Former smoking & 1.2579 & $1.0955,1.4447$ & $>0.001$ \\
Diabetes mellitus & 1.001 & $0.7845,1.2771$ & 0.9936 \\
Hypertension & 1.3129 & $1.1452,1.5055$ & 0.7782 \\
\hline
\end{tabular}

Model 1: unadjusted; model 2: adjusted for age, sex, smoking, diabetes, and hypertension. $C I$ confidence interval, $O R$ odds ratio

in epidemiological studies, classifying in no/mild, moderate, and severe periodontitis [36].

The significant association between strong coffee consumption and periodontitis remained significant after adjusting for age, sex, smoking, diabetes and hypertension. In line with other studies, high coffee consumption was significantly associated with a higher level of cigarette smoking, an important risk factor for periodontal disease [37, 38]. Smoking induces vasoconstriction and negatively influence fibroblast functions and induce collagen breakdown in periodontal tissues [39, 40]. Thus, we included smoking as a confounder variable and were still able to demonstrate association between coffee consumption and periodontitis. We also excluded the following covariables from regression analyses: education (proven evidence for no association with coffee consumption [41]) and Plaque Index (detected multicollinearity; variance inflation factors $=6.9$ ).

Furthermore, the confounder "stress" could not be included in our regression model, though it's proven association to periodontitis in clinical [42] as well as epidemiological studies [43]. The effect of stress on the body/ periodontitis is mostly mediated by a complex hormonal response system in the hypothalamus-pituitary-adrenal axis (HPA). In brief: activation of the HPA results in increased levels of cortisol, which can (1) inhibit T-cell immune response and thereby amplify the outgrowth of pathogenic micro-organism [43], (2) act as oxidative damage mediator, which can promote periodontal disease progression [44], (3) influences bone metabolism via apoptosis of osteocytes [44].

\section{Limitations}

The current findings showed an association between strong coffee consumption and periodontitis; however, a cross-sectional study design cannot address causality. Furthermore, findings derived from the northern German population cannot necessarily be generalized to other populations. Another limitation is the small sample size in participants drinking only decaffeinated coffee (strong consumption of decaffeinated coffee $n=16$ ). Analyses for potential associations between decaffeinated coffee and periodontitis could not be performed.

\section{Conclusion}

In this cross-sectional study, strong but not moderate coffee consumption was significantly associated with periodontitis, compared to participants with low coffee consumption. Influence of changes in coffee consumption on periodontal disease etiology and progression should be investigated in future prospective study designs, in order to identify strong coffee consumption as a risk factor of periodontitis and its progression.

Supplementary Information The online version contains supplementary material available at https://doi.org/10.1007/s00784-021-04208-9.

Author contribution Conceptualization: Carolin Walther, Birgit-Christiane Zyriax, Jan-Per Wenzel, Thomas Beikler, and Ghazal Aarabi; methodology: Carolin Walther, Birgit-Christiane Zyriax, Jan-Per Wenzel, Katrin Borof, and Ghazal Aarabi; formal analysis and investigation: Julia Struppek, Carolin Walther, Katrin Borof, and Ghazal Aarabi; writing — original draft preparation: Julia Struppek and Carolin Walther; writing - review and editing: Julia Struppek, Carolin Walther, Kübra Bunte, Birgit-Christiane Zyriax, Jan-Per Wenzel, Juliana Senftinger, Julius Nikorowitsch, Guido Heydecke, Udo Seedorf, Thomas Beikler, Katrin Borof, Carola Mayer, and Ghazal Aarabi; Resources: Kübra Bunte, Birgit-Christiane Zyriax, Jan-Per Wenzel, Juliana Senftinger, Julius Nikorowitsch, Guido Heydecke, Udo Seedorf, Thomas Beikler, Katrin Borof, Carola Mayer, and Ghazal Aarabi; Supervision: Birgit-Christiane Zyriax, Jan-Per Wenzel, Guido Heydecke, Thomas Beikler, and Ghazal Aarabi.

Funding Open Access funding enabled and organized by Projekt DEAL.

\section{Declarations}

Ethics approval This study was performed in line with the principles of the Declaration of Helsinki. Approval was granted by the local ethics committee of the Landesärztekammer Hamburg (State of Hamburg Chamber of Medical Practitioners, PV5131).

Consent to participate Informed consent was obtained from all individual participants included in the study. 
Conflict of interest The authors declare no competing interests.

Clinical Trial Registration: The study has been registered at ClinicalTrials.gov (NCT039934957).

The present study is reported according to the STROBE Guidelines [45]. All authors agree to be held accountable for all aspects of the present study.

Open Access This article is licensed under a Creative Commons Attribution 4.0 International License, which permits use, sharing, adaptation, distribution and reproduction in any medium or format, as long as you give appropriate credit to the original author(s) and the source, provide a link to the Creative Commons licence, and indicate if changes were made. The images or other third party material in this article are included in the article's Creative Commons licence, unless indicated otherwise in a credit line to the material. If material is not included in the article's Creative Commons licence and your intended use is not permitted by statutory regulation or exceeds the permitted use, you will need to obtain permission directly from the copyright holder. To view a copy of this licence, visit http://creativecommons.org/licenses/by/4.0/.

\section{References}

1. Kassebaum NJ, Bernabe E, Dahiya M, Bhandari B, Murray CJ, Marcenes W (2014) Global burden of severe periodontitis in 1990-2010: a systematic review and meta-regression. J Dent Res 93:1045-1053. https://doi.org/10.1177/0022034514552491

2. Peres MA, Macpherson LMD, Weyant RJ, Daly B, Venturelli R, Mathur MR, Listl S, Celeste RK, Guarnizo-Herreno CC, Kearns C, Benzian H, Allison P, Watt RG (2019) Oral diseases: a global public health challenge. Lancet 394:249-260. https://doi.org/10. 1016/S0140-6736(19)31146-8

3. Holtfreter B, Kocher T, Hoffmann T, Desvarieux M, Micheelis W (2010) Prevalence of periodontal disease and treatment demands based on a German dental survey (DMS IV). J Clin Periodontol 37:211-219. https://doi.org/10.1111/j.1600-051X.2009.01517.x

4. Shaikh HFM, Patil SH, Pangam TS, Rathod KV (2018) Polymicrobial synergy and dysbiosis: an overview. J Indian Soc Periodontol 22:101-106. https://doi.org/10.4103/jisp.jisp_385_17

5. Loos BG (2005) Systemic markers of inflammation in periodontitis. J Periodontol 76:2106-2115. https://doi.org/10.1902/jop.2005. 76.11-S.2106

6. Bretz WA, Weyant RJ, Corby PM, Ren D, Weissfeld L, Kritchevsky SB, Harris T, Kurella M, Satterfield S, Visser M, Newman AB (2005) Systemic inflammatory markers, periodontal diseases, and periodontal infections in an elderly population. J Am Geriatr Soc 53:1532-1537. https://doi.org/10.1111/j.1532-5415.2005. 53468. $\mathrm{x}$

7. da Silva MK, de Carvalho ACG, Alves EHP, da Silva FRP, Pessoa LDS, Vasconcelos DFP (2017) Genetic factors and the risk of periodontitis development: findings from a systematic review composed of 13 studies of meta-analysis with 71,531 participants. Int J Dent 2017:1914073. https://doi.org/10.1155/2017/1914073

8. Larsson L, Castilho RM, Giannobile WV (2015) Epigenetics and its role in periodontal diseases: a state-of-the-art review. J Periodontol 86:556-568. https://doi.org/10.1902/jop.2014.140559

9. AlJehani YA (2014) Risk factors of periodontal disease: review of the literature. Int J Dent 2014:182513. https://doi.org/10.1155/ 2014/182513

10. Wade WG (2021) Resilience of the oral microbiome. Periodontol 2000(86):113-122. https://doi.org/10.1111/prd.12365
11. Najeeb S, Zafar MS, Khurshid Z, Zohaib S and Almas K (2016) The role of nutrition in periodontal health: an update. Nutrients 8https://doi.org/10.3390/nu8090530

12. Dawson DR III, Branch-Mays G (2000) Gonzalez OA and Ebersole JL (2014) Dietary modulation of the inflammatory cascade. Periodontol 64:161-197. https://doi.org/10.1111/j.1600-0757. 2012.00458.x

13. Cecoro G, Annunziata M, Iuorio MT, Nastri L and Guida L (2020) Periodontitis, low-grade inflammation and systemic health: a scoping review. Medicina (Kaunas) 56https://doi.org/10.3390/ medicina56060272

14. Loftfield E, Freedman ND, Dodd KW, Vogtmann E, Xiao Q, Sinha R, Graubard BI (2016) Coffee drinking is widespread in the United States, but usual intake varies by key demographic and lifestyle factors. J Nutr 146:1762-1768. https://doi.org/10.3945/ jn. 116.233940

15. Gunter MJ, Murphy N, Muller DC, Riboli E (2018) Coffee drinking and mortality in 10 European countries. Ann Intern Med 168:380-381. https://doi.org/10.7326/L17-0689

16. Tsou SH, Hu SW, Yang JJ, Yan M and Lin YY (2019) Potential oral health care agent from coffee against virulence factor of periodontitis. Nutrients 11https://doi.org/10.3390/nu11092235

17. Song IS, Han K, Ko Y, Park YG, Ryu JJ, Park JB (2016) Associations between the consumption of carbonated beverages and periodontal disease: The 2008-2010 Korea national health and nutrition examination survey. Medicine (Baltimore) 95:e4253. https://doi.org/10.1097/MD.0000000000004253

18. Dommisch H, Kuzmanova D, Jönsson D (2000) Grant M and Chapple I (2018) Effect of micronutrient malnutrition on periodontal disease and periodontal therapy. Periodontol 78:129153. https://doi.org/10.1111/prd.12233

19. Song IS, Han K, Ryu JJ, Choi YJ, Park JB (2018) Coffee intake as a risk indicator for tooth loss in Korean adults. Sci Rep 8:2392. https://doi.org/10.1038/s41598-018-20789-0

20. Han K, Hwang E, Park JB (2016) Association between consumption of coffee and the prevalence of periodontitis: the 2008-2010 Korea National Health and Nutrition Examination Survey. PLoS ONE 11:e0158845. https://doi.org/10.1371/journ al.pone. 0158845

21. Hong SJ, Kwon B, Yang BE, Choi HG, Byun SH (2021) Evaluation of the relationship between drink intake and periodontitis using KoGES data. Biomed Res Int 2021:5545620. https://doi. org/10.1155/2021/5545620

22. Ng N, Kaye EK, Garcia RI (2014) Coffee consumption and periodontal disease in males. J Periodontol 85:1042-1049. https://doi. org/10.1902/jop.2013.130179

23. Machida T, Tomofuji T, Ekuni D, Azuma T, Takeuchi N, Maruyama T, Mizutani S, Kataoka K, Kawabata Y, Morita M (2014) Severe periodontitis is inversely associated with coffee consumption in the maintenance phase of periodontal treatment. Nutrients 6:4476-4490. https://doi.org/10.3390/nu6104476

24. Jagodzinski A, Johansen C, Koch-Gromus U, Aarabi G, Adam G, Anders S, Augustin M, der Kellen RB, Beikler T, Behrendt CA, Betz CS, Bokemeyer C, Borof K, Briken P, Busch CJ, Buchel C, Brassen S, Debus ES, Eggers L, Fiehler J, Gallinat J, Gellissen S, Gerloff C, Girdauskas E, Gosau M, Graefen M, Harter M, Harth V, Heidemann C, Heydecke G, Huber TB, Hussein Y, Kampf MO, von dem Knesebeck O, Konnopka A, Konig HH, Kromer R, Kubisch C, Kuhn S, Loges S, Lowe B, Lund G, Meyer C, Nagel L, Nienhaus A, Pantel K, Petersen E, Puschel K, Reichenspurner H, Sauter G, Scherer M, Scherschel K, Schiffner U, Schnabel RB, Schulz H, Smeets R, Sokalskis V, Spitzer MS, Terschuren C, Thederan I, Thoma T, Thomalla G, Waschki B, Wegscheider K, Wenzel JP, Wiese S, Zyriax BC, Zeller T, Blankenberg S (2019) Rationale and design of the Hamburg city health study. Eur J Epidemiol. https://doi.org/10.1007/s10654-019-00577-4 
25. World Medical A (2013) World Medical Association Declaration of Helsinki: ethical principles for medical research involving human subjects. JAMA 310:2191-2194. https://doi.org/10.1001/ jama.2013.281053

26. Nöthlings U, Hoffmann K, Bergmann MM, Boeing H (2007) Fitting portion sizes in a self-administered food frequency questionnaire. J Nutr 137:2781-2786. https://doi.org/10.1093/jn/137.12. 2781

27. Silness J, Loe H (1964) Periodontal Disease in Pregnancy. Ii. Correlation between Oral Hygiene and Periodontal Condtion. Acta Odontol Scand 22:121-135. https://doi.org/10.3109/0001635640 8993968

28. Eke PI, Page RC, Wei L, Thornton-Evans G, Genco RJ (2012) Update of the case definitions for population-based surveillance of periodontitis. J Periodontol 83:1449-1454. https://doi.org/10. 1902/jop.2012.110664

29. Organisation for Economic C-o and Development (1999) Classifying educational programmes: manual for ISCED-97 implementation in OECD countries. Organisation for Economic Co-operation and Development, Paris

30. Kamagata-Kiyoura Y, Ohta M, Cheuk G, Yazdani M, Saltzman MJ, Nakamoto T (1999) Combined effects of caffeine and prostaglandin E2 on the proliferation of osteoblast-like cells (UMR10601). J Periodontol 70:283-288. https://doi.org/10.1902/jop.1999. 70.3.283

31. Bezerra JP, da Silva LR, de Alvarenga Lemos VA, Duarte PM, Bastos MF (2008) Administration of high doses of caffeine increases alveolar bone loss in ligature-induced periodontitis in rats. J Periodontol 79:2356-2360. https://doi.org/10.1902/jop. 2008.080204

32. Tanaka K, Miyake Y, Sasaki S, Ohya Y, Matsunaga I, Yoshida T, Hirota Y, Hajime O, Kanzaki H, Kitada M, Horikoshi Y, Ishiko O, Nakai Y, Nishio J, Yamamasu S, Yasuda J, Kawai S, Yanagihara K, Wakuda K, Kawashima T, Narimoto K, Iwasa Y, Orino K, Tsunetoh I, Yoshida J, Iito J, Kaneko T, Sanfujinka K, Kamiya T, Kuribayashi H, Taniguchi T, Takemura H, Morimoto Y, Osaka M, Child Health Study G (2008) Beverage consumption and the prevalence of tooth loss in pregnant Japanese women: the Osaka Maternal and Child Health Study. Fukuoka Igaku Zasshi 99:80-9

33. Lu PZ, Lai CY, Chan WH (2008) Caffeine induces cell death via activation of apoptotic signal and inactivation of survival signal in human osteoblasts. Int J Mol Sci 9:698-718. https://doi.org/10. 3390/ijms9050698

34. Hasling C, Sondergaard K, Charles P, Mosekilde L (1992) Calcium metabolism in postmenopausal osteoporotic women is determined by dietary calcium and coffee intake. J Nutr 122:11191126. https://doi.org/10.1093/jn/122.5.1119

35. Barger-Lux MJ, Heaney RP (1995) Caffeine and the calcium economy revisited. Osteoporos Int 5:97-102. https://doi.org/10. 1007/BF01623310
36. Holtfreter B, Albandar JM, Dietrich T, Dye BA, Eaton KA, Eke PI, Papapanou PN, Kocher T, Joint EUUSAPEWG (2015) Standards for reporting chronic periodontitis prevalence and severity in epidemiologic studies: proposed standards from the Joint EU/ USA Periodontal Epidemiology Working Group. J Clin Periodontol 42:407-412. https://doi.org/10.1111/jcpe.12392

37. Klesges RC, Ray JW, Klesges LM (1994) Caffeinated coffee and tea intake and its relationship to cigarette smoking: an analysis of the Second National Health and Nutrition Examination Survey (NHANES II). J Subst Abuse 6:407-418. https://doi.org/10.1016/ s0899-3289(94)90334-4

38. Treur JL, Taylor AE, Ware JJ, McMahon G, Hottenga JJ, Baselmans BM, Willemsen G, Boomsma DI, Munafo MR, Vink JM (2016) Associations between smoking and caffeine consumption in two European cohorts. Addiction 111:1059-1068. https:// doi.org/10.1111/add.13298

39. Leite FRM, Nascimento GG, Scheutz F, Lopez R (2018) Effect of smoking on periodontitis: a systematic review and meta-regression. Am J Prev Med 54:831-841. https://doi.org/10.1016/j.amepre.2018.02.014

40. Sham AS, Cheung LK, Jin LJ, Corbet EF (2003) The effects of tobacco use on oral health. Hong Kong Med J 9:271-277

41. Rehm CD, Ratliff JC, Riedt CS, Drewnowski A (2020) Coffee consumption among adults in the United States by demographic variables and purchase location: analyses of NHANES 2011-2016 data. Nutrients 12:2463

42. Rai B, Kaur J, Anand SC, Jacobs R (2011) Salivary stress markers, stress, and periodontitis: a pilot study. J Periodontol 82:287-292. https://doi.org/10.1902/jop.2010.100319

43. Hilgert JB, Hugo FN, Bandeira DR, Bozzetti MC (2006) Stress, cortisol, and periodontitis in a population aged 50 years and over. J Dent Res 85:324-328. https://doi.org/10.1177/1544059106 08500408

44. Botelho J, Machado V, Mascarenhas P, Rua J, Alves R, Cavacas MA, Delgado A, João Mendes J (2018) Stress, salivary cortisol and periodontitis: a systematic review and meta-analysis of observational studies. Arch Oral Biol 96:58-65. https://doi.org/ 10.1016/j.archoralbio.2018.08.016

45. von Elm E, Altman DG, Egger M, Pocock SJ, Gotzsche PC, Vandenbroucke JP, Initiative S (2008) The Strengthening the Reporting of Observational Studies in Epidemiology (STROBE) statement: guidelines for reporting observational studies. J Clin Epidemiol 61:344-349. https://doi.org/10.1016/j.jclinepi.2007.11. 008

Publisher's Note Springer Nature remains neutral with regard to jurisdictional claims in published maps and institutional affiliations. 